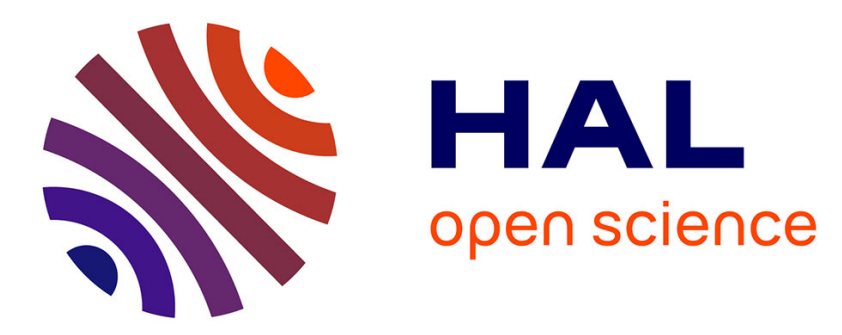

\title{
A Cognitive and Virtual Reality Treatment Program for the Fear of Flying
}

Margot Ferrand, Alexis Ruffault, Xavier Tytelman, Cécile Flahault, Vélina Négovanska

\section{- To cite this version:}

Margot Ferrand, Alexis Ruffault, Xavier Tytelman, Cécile Flahault, Vélina Négovanska. A Cognitive and Virtual Reality Treatment Program for the Fear of Flying. Aerospace Medicine and Human Performance, 2015, 86 (8), pp.723-727. 10.3357/AMHP.4211.2015 . hal-01317564

\section{HAL Id: hal-01317564 \\ https://hal.science/hal-01317564}

Submitted on 20 May 2016

HAL is a multi-disciplinary open access archive for the deposit and dissemination of scientific research documents, whether they are published or not. The documents may come from teaching and research institutions in France or abroad, or from public or private research centers.
L'archive ouverte pluridisciplinaire HAL, est destinée au dépôt et à la diffusion de documents scientifiques de niveau recherche, publiés ou non, émanant des établissements d'enseignement et de recherche français ou étrangers, des laboratoires publics ou privés. 
Evaluation of a cognitive and virtual reality treatment program for the fear of flying

Margot Ferrand, $\mathrm{MSc}^{1,2}$; Alexis Ruffault, MSc ${ }^{1}$; Xavier Tytelman, $\mathrm{MSc}^{2}$; Cécile Flahault, $\mathrm{PhD}^{1}$; Vélina Négovanska, $\mathrm{PhD}^{2}$

${ }^{1}$ Laboratoire de psychopathologie et processus de santé (EA 4057), Université Paris Descartes, Sorbonne Paris Cité, Boulogne-Billancourt, France

${ }^{2}$ Centre du Traitement de la Peur de l'Avion, Paris, France

Abstract word count: 245

Word count: 2791

Number of figures: 0

Number of tables: 2

\section{Acknowledgements}

The authors acknowledge the CTPA (Fear of Flying Treatment Centre) for providing access to the subjects, and the Flight Experience Company. Authors also acknowledge Catherine O'Malley for translation corrections.

\section{Conflicts of interest}

Three authors (MF, XT, VN) work at the CTPA, however they declare they have no financial interest. 


\begin{abstract}
Background: Passenger air transport has considerably increased in the past fifty years. It is estimated that between 7 and $40 \%$ of the population of industrialized countries is currently afraid of flying. Programs treating the fear of flying have been developed to meet this problem. This study measures the effectiveness of one of these programs by focusing on flight-related anxiety before the program and after the first flight following the intervention. Methods: One hundred and fifty seven individuals were recruited to participate in a 1-day intervention aiming at treating the fear of flying, and utilizing both cognitive behavioral techniques and virtual reality. Anxiety was measured with the Flight Anxiety Situations (FAS) and the Flight Anxiety Modality (FAM) questionnaires. Results: Statistical analyses were conducted on 145 subjects (69.7\% females; aged from 14 to 64$)$ after the exclusion of individuals with missing data. The results showed a decrease in flight-related anxiety for each subscale of the two questionnaires: the somatic $(\mathrm{d}=2.44)$ and cognitive anxiety $(\mathrm{d}=1.47)$ subscales of the FAM, and the general flight anxiety $(\mathrm{d}=3.20)$, the anticipatory flight anxiety $(\mathrm{d}=1.74)$ and the in-flight anxiety $(\mathrm{d}=1.04)$ subscales of the FAS. Conclusions: The effectiveness of the treatment program utilizing both cognitive behavioral techniques and virtual reality strategies for fear of flying reduced flight-related anxiety in the subjects in our study. Our results show that subjects demonstrated lower anxiety levels after the first flight following the program than before the intervention.
\end{abstract}

Keywords: flight phobia; anxiety; pluridisciplinary program 


\section{Background}

Since the beginning of the 1960's, passenger air transport has considerably increased [26]. The airplane has become the most common way of transporting individuals across industrialized countries during the past decades. The International Air Transport Association (IATA) has published the figure of more than 3 billion passengers having been transported in 2013. The Association predicts an increase of $31 \%$ in the number of passengers between 2012 and 2017 and that the figure of 4 billion individuals transported each year will soon be exceeded.

Despite the common idea of the airplane being the safest way to travel $[9,10,12]$, a lot of individuals remain scared of flying, and some are even afraid at the sight of an airplane. In Western countries, among individuals who suffer from a fear of flying, $14 \%$ have never flown, $6 \%$ say that they do not want to fly again, and $10 \%$ take a plane only when they do not have any other choice. In Europe, more than $20 \%$ of individuals argue that they have difficulties in taking the plane because of their fear of flying [26]. According to several studies, between 7 and $40 \%$ of the general population in industrialized countries suffer from the fear of flying (with all anxiety disorder comorbidities taken into account) [14, 23].

The Diagnostic and Statistical Manual of mental disorders (DSM-IV-TR) defines a phobia as a "marked and persistent fear that is excessive or unreasonable, cued by the presence or anticipation of a specific object or situation" (p.210) [1]. Fear of flying, classified in the situational type of phobia, answers each of the characteristics of phobia as mentioned above: it is an excessive fear, cued by the presence of an airplane or the anticipation of any situation linked to it (e.g., going to the airport, buying the tickets, ideas of a crash), and exposure to airplanes provokes an immediate anxiety response (which can become a panic attack). The fear of flying could also be the expression of other subtypes of phobia. Thus, 50 to $80 \%$ of individuals suffering from a fear of flying could present comorbidities $[8,14,20]$. Fear of flying is unique because it contains "classical" elements of the fear of flying (e.g., related to the airplane: fear of crash, turbulence, sounds, take off), but may also include other specific phobias such as claustrophobia, fear of heights, or aquaphobia. The etiology of the fear of flying seems to be multifactorial $[13,14,23]$ : factors stemming from the individual (e.g., psychiatric comorbidities, sensitivity of the vestibular system, bad flight experiences, lack of information), social factors (e.g., where the fear occurs by the observation of family or peers), and environmental factors (e.g., media reporting and reinforcement of erroneous beliefs, movies, TV shows, and plane crashes). In a study from Schindler and colleagues [14], $70 \%$ of the subjects reported that the information broadcast in the media strongly influenced their apprehensions and fear of flying.

The fear of flying is mostly the concern of industrialized countries (e.g., it represents an economic loss in terms of the sales of airline tickets). It involves a relatively large part of the general population, and impacts different spheres of the personal, social, and/or professional life of individuals $[14,18]$. Several treatment programs have been developed in order to address this issue [21]. Today, these programs have multiplied but their comparative effectiveness has been studied only in a limited way. Even if they do offer different types of interventions, they rarely take into account the co-morbid nature of fear of flying. The proposed interventions can be in a single or a group design, and their duration varies from a single day to several weeks. The monitoring of patients is not always assured after the interventions, and the programs contain a combination of different cognitive-behavioral techniques such as psychoeducation, exposure, and respiration training. To cite a few examples, there is Air France's "Apprivoiser l'avion" program, the VALK program in the Netherlands, "VisionAir" in Canada, "Fit to Fly" by Swiss Air, and "SOAR" in the USA.

In most cases these programs are developed either by airlines or pilots, and the intervention of a health care professional is not always present. This can be a disadvantage 
since the clinical complexity of fear of flying with co-morbid mental health conditions could benefit from the assistance of a trained mental health provider.

There are studies that have measured the efficacy of treatment programs of the fear of flying, some with control groups $[6,17,24]$. Other studies aim to measure the effectiveness of certain techniques of the whole program (e.g., exposure and the use of other cognitivebehavioral techniques), or to compare the programs two-by-two [15, 24, 28]. It seems to be essential to focus on the techniques that are used in the programs in order to know whether these techniques are suitable for the fear of flying. These first studies allowed for the promotion of guidelines for the treatment of the fear of flying [13, 15, 21]. Our study looks at how effective a defined program of strategies changes symptoms from before to immediately after treatment.

To optimize the treatment and monitoring of the patients, the most important issue appears to be the evaluation of anxiety related to the fear of flying instead of the proof of a specific intervention's effectiveness. The aim of this study is to assess a treatment program that follows the international guidelines highlighted by Van Gerwen and colleagues $[15,21$, 24], and Da Costa and colleagues [4]. We will consider the "Prêt à décoller" (i.e., ready to take off) program in Paris. In this initial study, we compare specific anxiety levels before the intervention and after the first flight following the intervention. We hypothesize that this 1day program will allow subjects to reduce their anxiety-related fear of flying after their first flight following the program when compared to their anxiety-related fear of flying before the program.

\section{Subjects.}

\section{Methods}

A total of 157 individuals gave their signed agreement to participate in this study and filled out the questionnaires before the program (baseline) and after their first flight following the intervention (follow-up). The questionnaires were filled out between September 2013 and May 2014. The inclusion criteria for the participation were: having an email address, an internet access at home or at work, taking a flight after attending the program, and filling out the questionnaire at baseline and follow-up. The subjects were systematically recruited among the patients attending the program, and no exclusion criteria have been defined. Twelve individuals have been excluded from statistical analyses due to missing data in their questionnaires. Finally, one hundred and forty five subjects $(69.7 \%$ females $)$ aged from 14 to 64 years old $(\mathrm{M}=37$; $\mathrm{SD}=11)$ were enrolled in this study.

Procedure.

The subjects completed a 1-hour phone interview with one of the professionals prior to their participation in the program, which screened for a diagnosis (i.e., type of fear, comorbidities, previous psychotherapeutic attempts). The subjects then received an email confirming their inclusion in the program. Four days before the 1-day intervention, subjects received another email with a link to fill out the questionnaires (baseline): the QEPA (i.e., Questionnaire d'Evaluation de la Peur de l'Avion) composed with the Flight Anxiety Situations (FAS) and the Flight Anxiety Modality (FAM) in their French version [25]. The subjects informed the professionals about the date of their next flight, following the intervention, by phone, email, or the day of the intervention so that we could send them the QEPA on time. The QEPA is filled out before the 1-day intervention (baseline) and after the first flight following the intervention (follow-up). If the subjects wanted more information, had questions about their flight, or needed psychological support before their flight, they could contact the professionals by phone or email. In case of comorbidities, the subjects could have a face-to-face interview with one of the professionals. 
Professionals and subjects were not blinded to the study hypotheses and aims. They knew that the intervention's purpose was to treat their fear of flying, and that its efficacy was measured. All the subjects were informed of their answers' use for this research and completed a signed consent to participate. Institutional ethical approval was sought and given to conduct this study.

\section{Intervention.}

The Centre de Traitement de la Peur de l'Avion (CTPA) (i.e., Fear of Flying Treatment Centre) is a psychology practice specialized in the treatment of the fear of flying. A Cognitive-Behavioral Therapy (CBT) psychologist conducted the 1-day intervention (the first and last authors, MF and $\mathrm{VN}$ ) in association with an instructor in aviation and aviation safety expert (the second author, XT) and two professional pilots with experience working with anxious individuals. The intervention follows the international guidelines provided in this field: the combination of CBT techniques, information about aviation safety, and virtualreality exposure $[4,19,24]$. The price of the treatment program is 430 euros for one day with up to 9 subjects.

Firstly, the CBT-trained psychologist informed the subjects about the etiology, the predisposal factors, the treatment methods, and the management of the anxiety linked to the fear of flying. These components, from the CBT techniques, are known to be more effective than a simple behavioral support [24]. The management of the anxiety related to the fear of flying was taught with relaxation and respiration techniques, using the Symbiofi ${ }^{\circledR}$ cardiac coherence software [19]. Studies suggest that a cardiac coherence software including biofeedback increases the efficacy of the treatment from 80 to $100 \%$ [27]. Moreover, the effects seem to be maintained up to 3 years after the intervention [28].

Secondly, the instructor in aviation and aviation safety expert taught the subjects about the planes' safety and functioning (e.g., turbulence, resistance, meteorological disturbances, management of mechanical failures). The pilots answered questions regarding the subjects' concerns during this second phase.

Thirdly, the intervention ended with a flight in a fixed simulator, where the subjects could pilot a Boeing 737 with one of the pilots. For the treatment of the fear of flying, the use of a non-moving simulator appears to be as effective as a real flight, and a moving simulator $[2,16,17]$.

The intervention that each patient participated in was exactly the same: with the same professionals at the same location and the same content.

\section{Equipment.}

Anxiety was assessed with the FAS and the FAM questionnaires [25] in their French version. The detailed questionnaires' reliabilities for each subscale are displayed in Table I. The psychometric characteristics of the scales and subscales have been shown to be excellent in our sample [25].

The FAS questionnaire is a self-reported outcome composed of 32 items measuring the levels of anxiety in several situations related to the flight experience on a 5-point Likert scale (ranging from 1 "no anxiety" to 5 "overwhelming anxiety"). The FAS questionnaire is divided between 3 subscales: (1) Generalized Flight Anxiety (GFA) which contains 7 items (minimum possible score $=7$; maximum possible score $=35$ ), (2) Anticipatory Flight Anxiety (AFA) which is composed of 12 items (minimum possible score $=12$; maximum possible score $=60$ ), and (3) In-Flight Anxiety (IFA) which contains 10 items (minimum possible score $=10$; maximum possible score $=50$ ). Three items are not part of the final score of the FAS questionnaire: items 19, 21, and 26.

The FAM questionnaire is a self-reported outcome that contains 18 items assessing the anxiety symptoms related to the flight on a 5-point Likert scale (ranging from 1 "not at all" to 5 "very intensely"). The FAM questionnaire separates 2 types of symptoms displayed in 2 
subscales: (1) the somatic modality (assessing the expression of physical symptoms of anxiety) composed of 11 items (minimum possible score $=11$; maximum possible score $=55$ ), and (2) the cognitive modality (reporting the presence of disturbing or negative thoughts) that contains 7 items (minimum possible score $=7$; maximum possible score $=35$ ).

Statistical analysis.

The data were analyzed using SPSS [5] after the exclusion of the subjects with missing data $(n=12)$. We compared the mean scores, for each subscale, between baseline and followup assessments with Student t-test at a $0.5 \%$ significance threshold. Effect sizes were calculated using Cohen's $d$ coefficient [3].

Table I. Test of internal consistency for each subscale's reliability.

\begin{tabular}{lccc}
\hline & \multicolumn{3}{c}{ Cronbach's $\alpha$} \\
\cline { 2 - 4 } Scale & T1 & T2 & Global \\
$(N=144)$ & $(N=145)$ & $(N=289)$ \\
\hline FAS & & & \\
$\quad$ Generalized & $.81^{* *}$ & $.89^{* *}$ & $.94^{* * *}$ \\
$\quad$ Anticipatory & $.82^{* *}$ & $.97^{* * *}$ & $.92^{* * *}$ \\
$\quad$ In-Flight & $.83^{* *}$ & $.93^{* * *}$ & $.89 * *$ \\
FAM & & & \\
$\quad$ Somatic & $.93^{* * *}$ & $.85^{* *}$ & $.97 * * *$ \\
$\quad$ Cognitive & $.89 * *$ & $.92^{* * *}$ & $.91^{* * *}$ \\
\hline
\end{tabular}

Notes:

FAS: Flyght Anxiety Situations; FAM: Flight Anxiety Modality

*** excellent; ** good; * acceptable

\section{Results}

We compared the means of each subscale of the FAS and FAM questionnaires between baseline and follow-up (see Table II). Statistical analyses showed a positive and significant effect for each subscale between the two assessment times (all $p$ 's $<.001$ ). Thus, the specific anxiety scores decreased after the first flight following the intervention, as compared to baseline scores. The scores of the GFA subscale of the FAS questionnaire $(\mathrm{t}(144)=28.444 ; p$ $<.001)$, the AFA subscale of the FAS questionnaire $(\mathrm{t}(144)=14.852 ; p<.001)$, the IFA subscale of the FAS questionnaire $(\mathrm{t}(144)=9.117 ; p<.001)$, the somatic modality of the FAM questionnaire $(\mathrm{t}(144)=27.068 ; p<.001)$, and the cognitive modality of the FAM questionnaire $(\mathrm{t}(144)=12.579 ; p<.001)$, decreased between baseline and follow-up.

Moreover, the effect size of the IFA subscale was large $(\mathrm{d}=1.04)$, while the effect sizes of the GFA subscale $(d=3.20)$, the AFA subscale $(d=1.74)$, the somatic modality $(d=2.44)$, and the cognitive modality $(\mathrm{d}=1.47)$ were very large $[3]$. 
Table II. Comparison of mean scores (M), standard deviations (SD), and effect sizes (d) at baseline as compared to after the first flight following the intervention.

\begin{tabular}{llcccccc}
\hline & & \multicolumn{2}{c}{ Baseline } & & \multicolumn{2}{c}{ Follow-up } & \\
\cline { 3 - 4 } \cline { 6 - 7 } Variables & & & & & & \\
FAS & Generalized & 24.60 & 5.457 & & 9.95 & 3.502 & $3.20^{* * * *}$ \\
& Anticipatory & 39.72 & 8.328 & & 24.49 & 9.187 & $1.74^{* * *}$ \\
& In-Flight & 30.00 & 8.413 & & 21.65 & 7.687 & $1.04^{* * *}$ \\
\multirow{2}{*}{ FAM } & Somatic & 32.11 & 8.473 & & 15.19 & 4.938 & $2.44^{* * *}$ \\
& Cognitive & 22.30 & 5.728 & & 13.80 & 5.875 & $1.47^{* * *}$ \\
\hline
\end{tabular}

Notes:

FAM: Flight Anxiety Modality; FAS: Flight Anxiety Situations. $* * * p<.001$ (as shown by $t$ test)

\section{Discussion}

The aim of this study was to test the efficacy of a treatment program for the fear of flying, hypothesizing that the specific anxiety levels would decrease between the baseline and follow up assessments. The program followed the international guidelines highlighted in previous studies in this field $[15,21]$.

The results are in line with our main hypothesis, thus they showed a positive significant effect for each subscale of anxiety related to the fear of flying between baseline and follow up measures with large to very large effect sizes. Therefore generalized flight anxiety (e.g., seeing a plane, hearing the sound of an airplane), anticipatory flight anxiety (e.g., decision to take a flight, buying tickets, driving to the airport), and in-flight anxiety (e.g., feeling turbulences, hearing the engine's sounds) decreased after the first flight following the 1-day intervention. Moreover, physical symptoms of anxiety (e.g., sweating, feeling one's heartbeat) and the cognitive symptoms of anxiety (e.g., negative thoughts, anticipating something going wrong, being afraid of dying) before and during the flight were better controlled by the subjects, and were less intense. This evolution allows us to conclude that the subjects were less anxious about flying after their first flight following the intervention than before attending the program. No differences have been shown between male and female subjects.

These results confirm the success of our treatment programs which combats fear of flying by utilizing three strategies: psychoeducation, CBT techniques, and exposure. By associating these three components, we find that the program's effectiveness is optimal and that anxiety decreases significantly after the intervention. Furthermore, our results suggest a benefit from utilizing trained professionals in these interventions, meaning that CBT-trained psychologists and aviation experts (i.e., aviation safety experts and pilots) may be a central pillar of successful treatment results.

Even if the results show the efficacy of the program, limitations must be outlined. First, the absence of a control group does not allow us to conclude that the observed effects are only due to the intervention or whether there are other factors as well. In fact, the price of the program makes difficult the establishment of a control group: subjects who pay for such an intervention should be allowed to get benefits from it. Second, the subjects and professionals were not blind to the study hypotheses (i.e., to measure the program's efficacy). Thus, the blinding of the subjects should be ensured for future studies in this field, in order to limit the bias of social desirability and the placebo effect. And third, the price of the program (i.e., 430 euros for the 1-day intervention) could have excluded individuals who cannot afford it. Future research in this field should assess the economic and professional status of the subjects.

In this study, we quantified the reduction of fear of flying anxiety symptoms in a population of patients using a specifically developed program building on cognitive 
behavioral treatment and virtual reality strategies. Future research could explore the specificity of the phobia of each participant and its particular intensity (e.g., crash, take off, sounds, landing, fear of being afraid, and fear of panic attacks). A more qualitative investigation of the fear of flying (e.g., including professional and economic status, comorbidities, and previous psychological support attempts) could bring more elements to improve the treatment programs of the fear of flying. With regard to our promising results, we wish to assess the persistence of our patient's gains at a future follow-up date.

\section{References}

[1] American Psychiatric Association. Diagnostic and Statistical Manual of Mental Disorders, Fourth Edition, Text Revision (DSM-IV-TR). 4th ed. Arlington, VA: American Psychiatric Association; 2000.

[2] Boyd D, Wetterneck C, Hart J. Potential Utility of Full Motion Flight Simulators for Treatment of Individuals with a Fear of Flying. Aviat, Space Environ Med. 2013;84(3):264-5.

[3] Cohen J. Statistical power analysis for the behavioral sciences. 2nd ed. Hillsdale, N.J: L. Erlbaum Associates; 1988. 567 p.

[4] Da Costa RT, Sardinha A, Nardi AE. Virtual Reality Exposure in the Treatment of Fear of Flying. Aviat Space and Environ Med. 2008;79(9):899-903.

[5] IBM SPSS Statistics for Mcintosh. Armonk, NY; 2013.

[6] Krijn M, Emmelkamp PMG, Ólafsson RP, Bouwman M, van Gerwen LJ, Spinhoven P et al. Fear of flying treatment methods: virtual reality exposure vs. cognitive behavioral therapy. Aviat Space Environ Med 2007;78:121-128.

[7] Laker M. Specific phobia : flight. Activ Nerv Super. 2012;54(3-4).

[8] Medialdea J, Tejada FR. Phobic fear of flying in aircrews: epidemiological aspects and comorbidity. Aviat Space Environ Med. 2005;76:566-8.

[9] Ministère de l'écologie, du développement durable et de l'énergie, \& Direction Générale de l'Aviation Civile. (2014). Transports : secteur aérien [Site gouvernemental]. Retrieved May 29, 2014, from http://www.developpement-durable.gouv.fr/-Analysesenquetes-et-statistiques-.html (Transports: aviation sector [governmental website]).

[10] Ministère de l'intérieur. (2014). Bilan annuel de la sécurité routière en France [Site gouvernemental]. Retrieved May 28, 2014, from http://www.securite-

routiere.gouv.fr/la-securite-routiere/l-observatoire-national-interministeriel-de-lasecurite-routiere/bilans-annuels/bilan-annuel-de-la-securite-routiere-en-france (Annual Review of road safety in France [governmental website]).

[11] Muhlberger A. Efficacy of a One-Session Virtual Reality Exposure Treatment for Fear of Flying. Psychother Res. 2003;13(3):323-36.

[12] National Safety Council. (2008). The most common causes of death due to injury in the United States. Retrieved from http://danger.mongabay.com/injury_death.htm

[13] Nousi A, Van Gerwen LJ, Spinhoven P. The Flight Anxiety Situations Questionnaire and the Flight Anxiety Modality Questionnaire: Norms for people with fear of flying. Travel Med Infect Dis. 2008;6(5):305-10.

[14] Oakes M, Bor R. The psychology of fear of flying (part I): A critical evaluation of current perspectives on the nature, prevalence and etiology of fear of flying. Travel Med Infect Dis. 2010;8(6):327-38.

[15] Oakes M, Bor R. The psychology of fear of flying (part II): A critical evaluation of current perspectives on approaches to treatment. Travel Med Infect Dis. 2010;8(6):33963. 
[16] Rothbaum BO, Anderson P, Zimand E, Hodges L, Lang D, Wilson J. Virtual Reality Exposure Therapy and Standard (in Vivo) Exposure Therapy in the Treatment of Fear of Flying. Behav Ther. 2006;37(1):80-90.

[17] Rothbaum BO, Hodges L, Anderson PL, Price L, Smith S. Twelve-month follow-up of virtual reality and standard exposure therapies for the fear of flying. J Consult Clin Psych. 2002;70(2):428-32.

[18] Saadat SH, Izadi M, Ahmadi K, Shahyad S. Non-Pharmacologic Treatments for Fear of Flying. Int J Travel Med Glob Health. 2014;2(1):31-7.

[19] Trimmel M, Burger M, Langer G, Trimmel K. Treatment of Fear of Flying: Behavioral, Subjective, and Cardiovascular Effects. Aviat Space Environ Med. 2014;85(5):550-62.

[20] Van Gerwen LJ, Delorme C, Van Dyck R, Spinhoven P. Personality pathology and cognitive-behavioral treatment of fear of flying. J Behav Ther and Exp Psychiatry. 2003;34:171-89.

[21] Van Gerwen LJ, Diekstra RFW, Arondeus JM, Wolfger R. Fear of flying treatment programs for passengers: an international update. Travel Med Infect Dis. 2004;2(1):2735.

[22] Van Gerwen LJ, Spinhoven P, Diekstra RFW, Van Dyck R. Multicomponent Standardized Treatment Programs for Fear of Flying: Description and Effectiveness. Cogn Behav Pract. 2002;(9):138-49.

[23] Van Gerwen LJ, Spinhoven P, Diekstra RFW, Van Dyck R. People who seek help for fear of flying: Typology of flying phobics. Behav Ther. 1997;28(2):237-51.

[24] Van Gerwen LJ, Spinhoven P, Van Dyck R. Behavioral and cognitive group treatment for fear of flying: A randomized controlled trial. J Behav Ther Exp Psy. 2006;37(4):358-71.

[25] Van Gerwen LJ, Spinhoven P, Van Dyck R, Diekstra RFW. Construction and psychometric characteristics of two self-report questionnaires for the assessment of fear of flying. Psychol Assessment. 1999;11(2):146.

[26] Van Gerwen LJ, Wolfger R. Fear_of_Flying. International Summer School on Aviation Psychology; 2007; Graz.

[27] Wiederhold BK, Jang DP, Gevirtz RG, Kim SI, Kim IY, Wiederhold MD. The treatment of fear of flying: a controlled study of imaginal and virtual reality graded exposure therapy. IEEE Trans Inf Technol Biomed. 2002;6(3):218-23.

[28] Wiederhold BK, Wiederhold MD. Three-Year Follow-Up for Virtual Reality Exposure for Fear of Flying. Cyberpsychol Behav. 2003;6(4):441-5. 